\title{
Epidemiology and Antimicrobial Susceptibility Trends of Methicillin-Resistant Staphylococcus aureus in a Tertiary Hospital
}

Thiago César Nascimento1,4, Vânia Lúcia da Silva1, Márcia Lucas Araújo ${ }^{1}$, Marina Barros Campos ${ }^{1}$, Alessandra Barbosa Ferreira-Machado', Dennis de Carvalho Ferreira ${ }^{2}$, Murilo Gomes Oliveira ${ }^{3}$, Cláudio Galuppo Diniz ${ }^{1}$

\section{Abstract}

Introduction: Staphylococcus aureus is a major cause of health care associated infections worldwide.

Objective: The aim of this work was to evaluate epidemiological characteristics and antimicrobial susceptibility of Methicillin-resistant S. aureus (MRSA) strains isolates from infections in a Brazilian tertiary hospital.

Methods: Clinical and epidemiological data of the patients were collected. Bacterial strains were isolated and identified using the classical identification tests. Antimicrobial susceptibility assays were performed using the disc-diffusion method.

Findings: A total of 590 samples of $S$. aureus were isolated from patients and $42.5 \%$ were characterized as MRSA. Considering the clinical specimens, most of samples were isolated from blood and tracheal secretion, catheter tip, surgical site swabs, wound secretion, exudates and urine. Overall, a high frequency of resistance was observed against ciprofloxacin, clindamycin, erythromycin, amikacin, gentamicin, trimethoprim-sulfamethoxazole, tetracycline and chloramphenicol. Association between death and multidrug-resistance in elderly patients, and death and occurrence of bacteremia by multidrug-resistant MRSA was observed.
1 Department of Parasitology, Microbiology and Immunology, Federal University of Juiz de Fora, 36036-900, Juiz de Fora,

Minas Gerais, Brazil.

2 School of Dentistry, Estácio de Sá University (UNESA), 22631-052, Rio de Janeiro, Brazil.

3 Department of Pharmaceutical Sciences, Federal University of Juiz de Fora, 36036900, Juiz de Fora, Minas Gerais, Brazil.

4 Department of Basic Nursing, Federal University of Juiz de Fora, 36036-900, Juiz de Fora, Minas Gerais, Brazil.

Contact information:

Cláudio Galuppo Diniz, PhD. Laboratory of Bacterial Physiology and Molecular Genetics, Department of Parasitology, Microbiology and Immunology.

Address: Institute of Biological Sciences, Federal University of Juiz de Fora, 36.036-900, Juiz de Fora, MG, Brazil. Tel-Fax: (55) 32 2102-3213

Đ claudio.diniz@ufjf.edu.br 
Conclusions: Our data are highly relevant for surveillance systems and to map on a wider scale the dynamics of circulation of MRSA and raise discussions on containment strategies and rational use of empiric chemotherapy.

\section{Keywords}

Staphylococcus aureus, antimicrobial susceptibility, methicillin-resistance.

\section{Introduction}

The Gram positive cocci Staphylococcus aureus is one of the most common microorganisms isolated from infections related to health care around the world. This scenario has gotten worse over time due to an increase in antimicrobial resistance rate, especially to methicillin, a penicillinase-resistant semisynthetic penicillin, antimicrobial of choice for the treatment of infections caused by antimicrobial-resistant $S$. aureus [1-3].

Methicillin-resistant $S$. aureus (MRSA) are resistant to other penicillins other $\beta$-lactams such as cephalosporins, carbapenems and monobactams [4]. These bacteria, initially related to infections associated to health care (hospital-acquired methicillin-resistant Staphylococcus aureus HA-MRSA), nowadays also represent a major problem in the community (community-associated methicillinresistant Staphylococcus aureus (A-MRSA) $[5,6]$. While the community-associated MRSA diseases are related to skin infections, the more severe clinical infections are more frequently related to hospitalized patients [7].

Although in Brazil, researches show a high frequency of MRSA colonization in patients with bacteremia, $[8,9]$ the most of the scientific data considering epidemiology and antimicrobial susceptibility patterns of MRSA to other antimicrobial, are originated in other countries. Thus, the available information is not, indeed, representative of the Brazilian reality, which makes difficult to guide the empirical chemotherapy. In this respect, considering the worldwide spread of MRSA and the lack of regional data on HA-MRSA epidemiology and antimicrobial susceptibility patterns, the aim of this study was to describe epidemiological characteristics and antimicrobial susceptibility trends of MRSA strains associated to patients admitted to a tertiary hospital, between 2005 and 2010, in Brazil.

\section{Methods}

The study was conducted at a teaching hospital in Juiz de Fora, MG, Brazil. It is a tertiary institution with 146 beds, and six of them are in an Intensive Care Unit (ICU). A total of 590 samples of $S$. aureus were isolated and identified from different clinical specimens from patients admitted between 2005 and $42.5 \% \quad(n=251)$ were characterized as MRSA. Considering only the non-replicate isolates, 103 MRSA strains were considered in this study (Table 1), which was approved by the Ethics Committee of the Federal University of Juiz de Fora (certificate no. 267/2011). Clinical and epidemiological data of the patients were collected from medical records and record books from the clinical microbiology laboratory Prof. Maurilio Baldi at the UFJF Teaching Hospital.

All the clinical specimens were inoculated in Mannitol Salt Agar (Difco, USA) with a $0.001 \mathrm{~mL}$ sterile loop and incubated at $35.5^{\circ} \mathrm{C}$ for up to 48 hours. Bacterial strains (3 to 5 colonies/clinical specimens) in monomicrobial cultures were isolated and identified using the classical identification tests [10]. Antimicrobial susceptibility assays were performed on Mueller-Hinton agar (HiMedia) using the discdiffusion method and growth inhibition zones were interpreted according to the Clinical and Laboratory 
Table 1. Epidemiological parameters and frequency of antimicrobial resistance in MRSA strains associated to patients admitted to a tertiary hospital over a 6-year period.

\begin{tabular}{|c|c|c|c|c|c|c|}
\hline \multirow{3}{*}{ Epidemiological parameters } & \multicolumn{6}{|c|}{ Sampled period } \\
\hline & 2005 & 2006 & 2007 & 2008 & 2009 & 2010 \\
\hline & $(n=25)$ & $(n=13)$ & $(n=27)$ & $(n=21)$ & $(n=10)$ & $(n=07)$ \\
\hline \multicolumn{7}{|l|}{ Gender } \\
\hline Male & $72.0 \%$ & $69.2 \%$ & $74 \%$ & $66.6 \%$ & $70.0 \%$ & $71.4 \%$ \\
\hline Female & $28.0 \%$ & $30.8 \%$ & $26 \%$ & $33.4 \%$ & $30.0 \%$ & $28.6 \%$ \\
\hline Average age (years) & 50.2 & 54.9 & 52.2 & 56.5 & 58.5 & 64.4 \\
\hline \multicolumn{7}{|l|}{ Type of Infection } \\
\hline Bacteremia & $4.0 \%$ & $23.1 \%$ & $22.2 \%$ & $33.3 \%$ & $30.0 \%$ & $14.3 \%$ \\
\hline Catheter bacteremia & $12.0 \%$ & $30.7 \%$ & $11.1 \%$ & $14.3 \%$ & $10.0 \%$ & $0.0 \%$ \\
\hline Surgical Site & $28.0 \%$ & $0.0 \%$ & 18.5 & $14.3 \%$ & $0.0 \%$ & $0.0 \%$ \\
\hline Wound infection & $0.0 \%$ & $0.0 \%$ & $11.1 \%$ & $4.8 \%$ & $10.0 \%$ & $14.3 \%$ \\
\hline Digestive system & $8.0 \%$ & $0.0 \%$ & $7.4 \%$ & $0.0 \%$ & $0.0 \%$ & $0.0 \%$ \\
\hline Musculoskeletal & $8.0 \%$ & $0.0 \%$ & $3.8 \%$ & $0.0 \%$ & $0.0 \%$ & $0.0 \%$ \\
\hline Respiratory system & $36.0 \%$ & $46.2 \%$ & $18.5 \%$ & $23.8 \%$ & $50.0 \%$ & $71.4 \%$ \\
\hline UTI & $4.0 \%$ & $0.0 \%$ & $7.4 \%$ & $9.5 \%$ & $0.0 \%$ & $0.0 \%$ \\
\hline \multicolumn{7}{|l|}{ Clinical specimens } \\
\hline Blood & $20.0 \%$ & $15.4 \%$ & $18.5 \%$ & $38.1 \%$ & $30.0 \%$ & $14.3 \%$ \\
\hline Tracheal secretion & $20.0 \%$ & $30.8 \%$ & $18.5 \%$ & $14.3 \%$ & $50.0 \%$ & $71.4 \%$ \\
\hline Urine & $4.0 \%$ & $0.0 \%$ & $7.5 \%$ & $9.5 \%$ & $0.0 \%$ & $0.0 \%$ \\
\hline Catheter tip & $16.0 \%$ & $30.8 \%$ & $11.1 \%$ & $19.0 \%$ & $10.0 \%$ & $0.0 \%$ \\
\hline Exudates & $12.0 \%$ & $23.0 \%$ & $22.2 \%$ & $4.8 \%$ & $10.0 \%$ & $14.3 \%$ \\
\hline Surgical Site Swabs & $28.0 \%$ & $0.0 \%$ & $22.2 \%$ & $14.3 \%$ & $0.0 \%$ & $0.0 \%$ \\
\hline \multicolumn{7}{|l|}{ Patient evolution } \\
\hline Discharged & $56.0 \%$ & $46.1 \%$ & $55.5 \%$ & $61.9 \%$ & $30.0 \%$ & $57.1 \%$ \\
\hline Death & $36.0 \%$ & $53.9 \%$ & $44.5 \%$ & $38.1 \%$ & $60.0 \%$ & $42.9 \%$ \\
\hline Transference & $8.0 \%$ & $0.0 \%$ & $0.0 \%$ & $0.0 \%$ & $10.0 \%$ & $0.0 \%$ \\
\hline \multicolumn{7}{|l|}{ Hospital section } \\
\hline Infirmary & $24.0 \%$ & $23.1 \%$ & $22.2 \%$ & $42.9 \%$ & $40.0 \%$ & $14.3 \%$ \\
\hline Surgery & $36.0 \%$ & $23.1 \%$ & $29.6 \%$ & $14.3 \%$ & $0.0 \%$ & $14.3 \%$ \\
\hline Intensive care & $36.0 \%$ & $53.8 \%$ & $44.4 \%$ & $33.3 \%$ & $50.0 \%$ & $71.4 \%$ \\
\hline Pediatric & $4.0 \%$ & $0.0 \%$ & $0.0 \%$ & $9.5 \%$ & $10.0 \%$ & $0.0 \%$ \\
\hline BMT & $0.0 \%$ & $0.0 \%$ & $3.8 \%$ & $0.0 \%$ & $0.0 \%$ & $0.0 \%$ \\
\hline
\end{tabular}


Standards Institute (CLSI) [11]. Antimicrobial discs amikacin $(30 \mu \mathrm{g})$, ciprofloxacin $(5 \mu \mathrm{g})$, clindamycin $(2 \mu \mathrm{g})$, chloramphenicol $(30 \mu \mathrm{g})$, erythromycin $(15 \mu \mathrm{g})$, gentamicin $(10 \mu \mathrm{g})$, trimethoprim-sulfamethoxazole $(25 \mu \mathrm{g})$, tetracycline $(30 \mu \mathrm{g})$ and were of commercial grade (Laborclin Ltda, Brazil). To evaluated the resistant to vancomycin E-test ${ }^{\circledR}$ was used (AB Biodisk, Solna, Sweden). MRSA was detected by resistance to cefoxitin $(30 \mu \mathrm{g})$ and oxacillin $(1 \mu \mathrm{g})$ disks. Staphylococcus aureus ATCC 25923 was used for quality control. Besides the descriptive analysis, univariate analysis were performed estimating the odds ratios (OR) with their respective 95\% confidence intervals $(\mathrm{Cl})$ to verify the associations between microbial resistance with discharged, transferred and deceased patients. The same analysis were performed among the type of MRSA infection and patient's age and outcome $(p<0.05)$. For means comparisons the Mann-Whitney test was used. The comparison of each factor was done by the non parametric Fisher's exact test.

\section{Results}

Detailed clinical and epidemiological characteristics of the patients are presented in table 1. Overall, $71 \%$ of bacteria were recovered from male patients and $29 \%$ from female. The average age was 54.4 years old. Overall, positive correlations between age or gender, and MRSA infected patients were not observed ( $p=1.00$ ). Although mainly associated to patients admitted in intensive care unit (43.7\%), MRSA were also isolate from patients admitted to adult infirmary (28.1\%), surgical unit (23.3\%), pediatrics (3.9\%) and bone marrow transplantation unit (1\%). Considering the associated infections, 34\% and $20.4 \%$ of the samples were isolated from respiratory tract and bacteremia infections, respectively. MRSA was also isolated from surgical site, catheterrelated bacteremia, wound infections, infections of the musculoskeletal system, tract urinary and digestive system.
Considering the clinical specimens, most of samples were isolated from tracheal secretion and blood (26.2\% and $23.3 \%$ respectively) followed by surgical site swabs, catheter tip, exudates, wound secretion and urine (Table 1). Regarding to the patients, 53.4\% were discharged, $43.6 \%$ died and 3\% were transferred to other hospitals.

Overall, a high frequency of resistance was observed against ciprofloxacin (92.5\%), clindamycin (89.7\%), erythromycin (86.9\%), amikacin (73.8\%), gentamicin (70\%), trimethoprim-sulfamethoxazole (63.5\%), tetracycline (60.7\%) and chloramphenicol (52.3\%). No bacterial resistance was observed against vancomycin (Figure 1).

Association between death and multirresistant MRSA was observed in elderly patients (OR=3.5795\% Cl: 0.3-38.8). Association was also observed between death and the occurrence of bacteremia in patients with multirresistant MRSA (OR=1.57-95\% $\mathrm{Cl}$ : 0.2-10.4). However these associations were not considered significant.

When considering MRSA occurrence over time and their antimicrobial susceptibility, alterations in the resistance patterns were observed. In 2005, from the tested drugs, the most effective antimicrobial was chloramphenicol, and high resistance levels were observed against amikacin, ciprofloxacin, clindamycin, erythromycin, gentamicin, trimethoprim-sulfamethoxazole and tetracycline. In 2006, increased resistance was observed against all tested drugs with rates of $100 \%$ resistance against ciprofloxacin, clindamycin, gentamicin, and trimethoprim-sulfamethoxazole. In the subsequent two years, decreased resistance was observed, especially in 2008, with exception for chloramphenicol in 2007. In 2009 it was observed high levels of sensitivity to amikacin, gentamicin, trimethoprimsulfamethoxazole and tetracycline (90\%). In 2010, there was a re-emergence of high resistance levels (100\%), especially against ciprofloxacin, clindamycin and erythromycin. Considering amikacin, gentamicin, trimethoprim-sulfamethoxazole and tetra- 
Figure 1: Antimicrobial susceptibility of Methicillin-resistant Staphylococcus aureus (MRSA) in a tertiary hospital over a 6-year period. AK, amikacin; CP, ciprofloxacin; CD, clindamycin; CL, chloramphenicol; EM, erytromycin; GM, gentamicin, TS, trimethoprim-sulfamethoxazole; TE, tetracycline; VA, vancomycin.

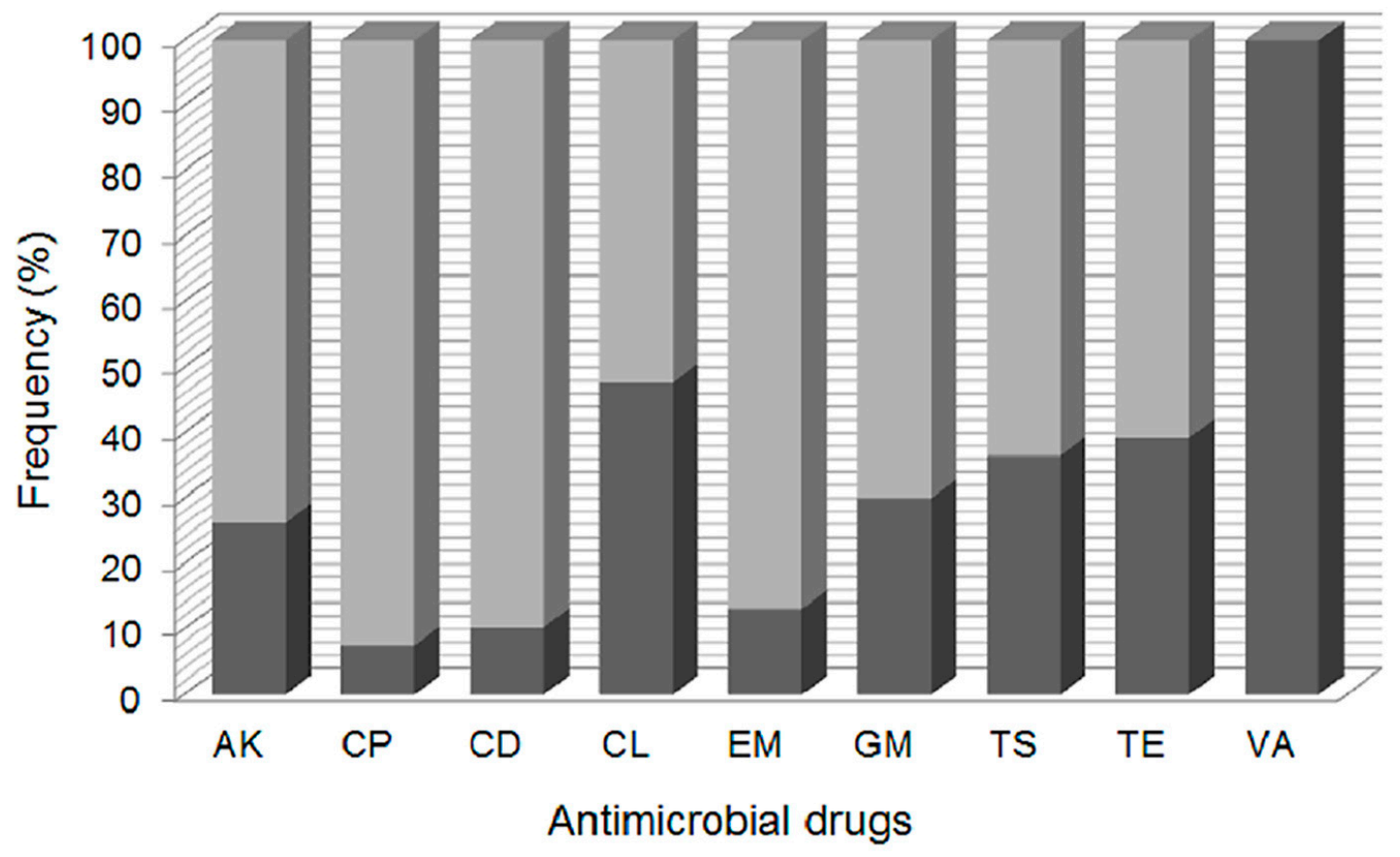

Sensitivity

Resistance

cycline, although it has been observed an increased resistance compared to the previous year, the resistance rates remained relatively low (28.6\%).

\section{Discussion}

Methicillin-resistant Staphylococcus aureus has become a global problem and active surveillance for this pathogen, with appropriate prevention measures, can reduce its infections rates and reduce treatment costs [12]. This study showed the clinical epidemiology of MRSA isolates from inpatients, identifying the distribution of this pathogen in different sections, associated with gender and average and more age type of infection, clinical specimens, and patient evolution of a teaching hospital. The results obtained demonstrate there was no statistically significant difference when the mean age of patients was compared among the years of the study ( $p>0.05)$. The incidence of MRSA infections is among the highest in the elderly population [13]. Study conducted in Sacramento, EUA, demonstrated that the average age of health care associated-MRSA patients was 54, which was 15 years older than the average age of patients with community associated-MRSA [14].

It is accepted that morbidity and mortality rates especially from infections with MRSA in bloodstream tend to be even greater in the elderly due to their physiological conditions and immunological status [15]. The impact of methicillin-resistance on mortality among patients infected with $S$. aureus has been primarily evaluated in patients with bacteremia, and the results were variable $[8,16]$. A meta-analysis involving studies with mortality data published between the years 1980 to 2000 was performed. Among 31 cohort studies including 3.963 patients, of whom 34\% were infected with 
MRSA, there was a significant increase in mortality associated with bacteremia [17]. Although there are few national data to compare our results, according to the literature methicillin-resistance significantly increased in the early 2000s in developed regions, such as the European countries [18] and the USA [19] and developing regions such as Latin America [20].

In Brazil, oxacillin is used as penicillinase-resistant semisynthetic penicillin, being oxacillin-resistant $S$. aureus (ORSA) equivalent to the MRSA strains in other regions. Reports from different hospitals between 1997 and 2001 with totalizing 1.516 S. aureus samples showed resistance rates of oxacillin resistance as of 3.8\% [21]. Reports comprising the period between 2005 and 2008, involving 2.218 samples, showed ORSA occurrence of $31.0 \%$, and most of these bacteria were also resistant against erythromycin, clindamycin, ciprofloxacin, and levofloxacin [22]. With regard to the ORSA observations, our data corroborate these previous studies. An increase in MRSA-associated hospital infections has been reported in intensive care units in USA, which ranged from only $2 \%$ in 1974 to rates of $22 \%$ in 1995 and 64\% in 2004 [23]. Subsequent studies showed stabilization in this tendency with rates of 56\% between 2006 and 2007 [24].

Another study conducted in a teaching hospital in the USA, which evaluated MRSA colonization or infections in hospitalized patients revealed that the most common types of infections were bacteremia (28\%), pneumonia (20\%), soft tissue infections (16\%), and bones or joints infections (16\%) [25]. Overall, the most frequently reported risk factors related to the acquisition of MRSA bacteremia include previous antibiotic chemotherapy, prolonged stay in ICU, previous MRSA infection and colonization, use of invasive devices such as central venous catheters and urinary catheter, previous hospitalization and presence of co-morbidities $[9,26]$.

The therapy used for MRSA infections is still rather limited. Some drugs have been used in recent years such as dalfopristin, linezolid, tigecycline and daptomycin $[27,28]$. However, the use of vancomycin is still the choice for treatment of these infections. The increase use of glycopeptides has facilitated the selection of resistance and the high toxicity caused in the human body, have shown the necessity of the restricted use of these antimicrobials $[29,30]$.

As a whole, the dynamics of antimicrobial resistance, observed in this study, show that the widespread use of ciprofloxacin, clindamycin and erythromycin should not be encouraged as the first empiric therapy option. By the other hand, the effectiveness of drugs such as chloramphenicol might be related to its low prescription over the years in our region. Based on results from antimicrobial susceptibility testing, the use of amikacin, gentamicin, tetracycline and trimethoprim-sulfamethoxazole should be sustained due to the variations observed for their effectiveness among the isolated bacteria.

We observed vancomycin as the most effective drug; other authors also suggest that it should be used only for serious infections, when other antimicrobials are without therapeutic effect $[29,30]$. Historically, the occurrence of antimicrobial resistance is inevitable. This is due to the natural species evolution caused by environmental selective pressures. In this respect, retrospective studies on antimicrobial susceptibility patterns should improve strategies to limit the emergence of multi-drug-resistant bacterial strains.

Our data are highly relevant not only for surveillance systems, but to map on a wider scale the dynamics of circulation of such microorganism and raise discussions on containment strategies and rational use of empiric chemotherapy.

\section{Conclusion}

This study showed relevant data on the levels of MRSA in critical areas and associated specimens respiratory tract secretions and blood. The high levels of antimicrobial resistance suggest the extent of 
the phenomenon and confirm data from the recent literature on the nature of the multidrug-resistant strains of S. aureus. Retrospective studies on antimicrobial susceptibility patterns should improve strategies to limit the emergence of multi-drugresistant bacteria. Our data are highly relevant for surveillance systems and to map on a wider scale the dynamics of circulation of MRSA and raise discussions on containment strategies and rational use of empiric chemotherapy

\section{Acknowledgments}

The authors are grateful to the Programa de PósGraduação em Saúde - Universidade Federal de Juiz de Fora (PPGS/UFJF). The authors are also grateful to staff from the Laboratory Prof. Maurilio Baldi, and Suzane F. Silva, Pedro P. Castro, Marina O. Fajardo, Débora M. Coelho, for technical help with the medical records and record books from the clinical microbiology laboratory.

\section{Funding}

The authors are grateful to Fundação de Amparo à Pesquisa de Minas Gerais (FAPEMIG) and Conselho Nacional de Desenvolvimento Científico e Tecnológico (CNPq) for financial support.

\section{Competing and conflicting interests}

The authors declare that they have no conflict of interest.

\section{References}

1. Boucher HW, Corey GR. Epidemiology of methicillin-resistant Staphylococcus aureus. Clin Infect Dis 2008; 46: 344-9.

2. Morton AP, Clements AC, Doidge SR, Stackelroth J, Curtis M, Whitby M. Surveillance of healthcare-acquired infections in Queensland, Australia: data and lessons from the first 5 years. Infect Control Hosp Epidemiol 2008; 29: 695-701.

3. Rosenthal VD, Maki DG, Mehta A, Alvarez-Moreno C, Leblebicioglu H, Hiquera $F$, et al. International Nosocomial Infection Control Consortium report, data summary for 20022007, issued January 2008. Am J Infect Control 2008; 36: 62737.

4. Ito T, Okuma K, Ma XX, Yuzama H, Hiramatsu K. Insights on antibiotic resistance of Staphylococcus aureus from its whole genome: genomic island SCC. Drug Resist. Updat 2003; 6: 4152.

5. Chambers HF. The changing epidemiology of Staphylococcus aureus? Emerg. Infect. Dis 2001; 7: 178-82.

6. Haley CC, Mittal D, Laviolette A. Methicillin-resistant Staphylococcus aureus infection or colonization present at hospital admission: multivariable risk factor screening to increase efficiency of surveillance culturing. J Clin Microbiol 2007; 45: 3031-38.

7. Gorwitz RJ, Kruszon-Moran D, McAllister SK. Communityassociated methicillin-resistant Staphylococcus aureus: epidemiology and update. J Infect Dis 2008; 197: 1226-34.

8. Conterno LO, Wey SB, Castelo A. Risk factors for mortality in Staphylococcus aureus bacteremia. Infect Control Hosp Epidemiol 1998; 19: 32-7.

9. Guilarde AO, Turchi MD, Martelli CM, Primo MG. Staphylococcus aureus bacteraemia: incidence, risk factors and predictors for death in a Brazilian teaching hospital. J Hosp Infect 2006; 63: 330-6.

10. Bannerman TL, Peacock SJ. Staphylococcus, Micrococcus and other catalase-positive cocci. In: Murray PR, Baron EJ, Jorgensen JH, Landry ML, Pfaller MA, editors. Manual of clinical microbiology. 9th ed. Washington [DC]: ASM Press; 2007. pp 390-411.

11. Clinical Laboratory Standards Institute (CLSI). Performance standards for antimicrobial susceptibility testing; Twentieth informational supplement. CLSI document M100eMS20. Wayne [PA]. Clinical Laboratory Standards Institute; 2010.

12. Azeez-Akande $O$. Global trend of methicillin-resistant Staphylococcus aureus and emerging challenges for control. Afr J Cln Exper Microbiol 2010; 1: 150-8.

13. Kuehnert MJ, Hill HA, Kupronis BA, Tokars JI, Solomon SL, Jernigan DB. Methicillin-resistant Staphylococcus aureus hospitalizations, United States. Emerg Infect Dis 2005; 11: 86872. 
14. Huang H, Flynn NM, King JH, Monchaud C, Morita M, Cohen SH. Comparisons of Community-Associated Methicillin-Resistant Staphylococcus aureus (MRSA) and Hospital-Associated MSRA Infections in Sacramento, California. J Clin Microbiol 2006; 44 2423-7.

15. High K. Infection as a cause of age-related morbidity and mortality. Ageing Res Rev 2004; 3: 1-14.

16. Selvey LA, Whitby M, Johnson B. Nosocomial methicillinresistant Staphylococcus aureus bacteremia: is it any worse than nosocomial methicillin sensitive Staphylococcus aureus bacteremia? Infect Control Hosp Epidemiol 2000; 21: 645-8.

17. Cosgrove SE, Sakoulas G, Perencevich EN, Schwaber MJ, Karchmer AW, Carmeli Y. Comparison of mortality associated with methicillin-resistant and methicillin susceptible Staphylococcus aureus bacteremia: a meta-analysis. Clin Infect Dis 2003; 36: 53-9.

18. European Antimicrobial Resistance Surveillance System (EARSS). 2005 <http://www.rivm.nl/earss/database.html>

19. National Nosocomial Infections Surveillance (NNIS) System Report. Data summary from january 1992 through june 2004. Am J Infect Control 2004; 32: 470-85.

20. Diekema DJ, Pfaller MA, Scmitz FJ, Smayevsky J, Bell J, Jones RN, et al. Survey of infections due to Staphylococcus species: frequency of occurrence and antimicrobial susceptibility of isolates collected in the United States, Canada, Latin America, Europe, and the Western Pacific Region for the SENTRY antimicrobial surveillance program, 1997-1999. Clin Infect Dis 2001; 32: 114-32.

21. Sader HS, Jones RN, Gales AC, Silva JB, Pignatari AC, Sentry Participants Group. Sentry antimicrobial surveillance program report: latinamerican and brazilian results for 1997 through 2001. Braz J Infect Dis 2004; 8: 25-79.

22. Gales AC, Sader HS, Ribeiro J, Zoccoli C, Barth A, Pignatari AC. Antimicrobial susceptibility of gram-positive bacteria isolated in brazilian hospitals participating in the SENTRY program (20052008). Braz J Infect Dis 2009; 13: 90-8.

23. Klevens RM, Edwards JR, Tenover FC, McDonald LC, Horan T, Gaynes R. Changes in the epidemiology of methicillin-resistant Staphylococcus aureus in intensive care units in US hospitals, 1992-2003. Clin Infect Dis 2006; 42: 389-91.

24. Hidron Al, Edwards JR, Patel J, Horan TC, Sievert DM, Pollock DA, et al. NHSN annual update: antimicrobial-resistant pathogens associated with healthcare-associated infections: annual summary of data reported to the National Healthcare Safety Network at the Centers for Disease Control and Prevention, 2006-2007. Infect Control Hosp Epidemiol 2008; 29: 996-1011.

25. Huang SS, Platt R. Risk of methicillin-resistant Staphylococcus aureus infection after previous infection or colonization. Clin Infect Dis 2003; 36: 281-5.
26. Carnicer-Pont D, Bailey KA, Mason BW, Walker AM, Evans $M R$, Salmon RL. Risk factors for hospital-acquired methicillinresistant Staphylococcus aureus bacteraemia: a case-control study. Epidemiol Infect 2006; 134: 1167-73.

27. Aksoy DY, Unal S. New antimicrobial agents for the treatment of Gram-positive bacterial infections. Clin Microbiol Infect 2008; 14: $411-20$.

28. Streit JM, Jones RN, Sader HS, Fritsche TR. Assessment of pathogen occurrences and resistance profiles among infected patients in the intensive care unit: report from the Sentry antimicrobial surveillance program (North America, 2001). Intern J Antimcrob Agents 2004; 24: 111-8.

29. Hiramatsu K, Cui L, Kuroda M, Ito T. The emergence and evolution of methicillin-resistant Staphylococcus aureus. Trends Microbiol 2001; 9: 486-93.

30. Rybak MJ. The pharmacokinetic and pharmacodynamic properties of vancomycin. Clin Infect Dis 2006; 42: 35-9.

\section{Comment on this article:}

\section{f) $[$ in $8+\boldsymbol{S} P$}

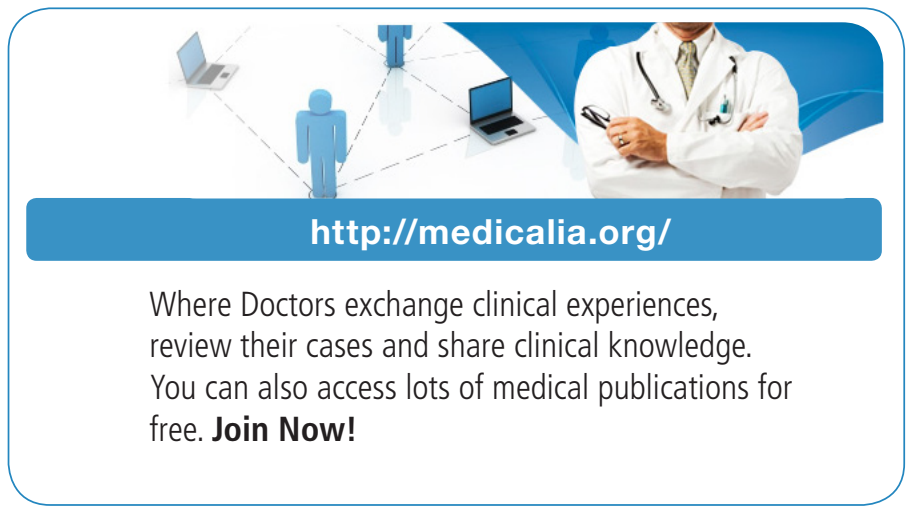

Publish with iMedPub

\section{http://www.imed.pub}

International Archives of Medicine is an open access journal publishing articles encompassing all aspects of medical science and clinical practice. IAM is considered a megajournal with independent sections on all areas of medicine. IAM is a really international journal with authors and board members from all around the world. The journal is widely indexed and classified Q1 in category Medicine. 